\title{
Detailed description of RBA-banded chromosomes of river buffalo (Bubalus bubalis L.)
}

\author{
D. DI BERARDINO and L. IANNUZZI \\ Animal Production Institute, Faculty of Agriculture, University of Naples \\ 80055 Portici, Naples, Italy
}

\begin{abstract}
Summary
The RBA banding pattern of river buffalo chromosomes and its diagrammatic representation are presented as a "model" for the definition of a standard RBA-banded karyotype for this species. A change in the current system of nomenclature for the Bovidae is also suggested to facilitate comparative studies among the members of the family.
\end{abstract}

Key words : River buffalo, RBA banding, chromosomes.

\begin{abstract}
Résumé
Description des chromosomes marqués en bandes $R$ du buffle de rivière (Bubalus bubalis L.)
\end{abstract}

Les bandes R (RBA technique) des chromosomes du buffle de rivière et son idiogramme sont présentés en tant que modèle pour la définition d'un caryotype standard de cette espèce. Cet article propose également un changement dans le système de la nomenclature des bovidés qui faciliterait les études comparatives entre membres de cette famille.

Mots clés : Buffle de rivière, bandes $R$, chromosomes.

\section{Introduction}

As known, the species Bubalus bubalis $\mathrm{L}$. includes 2 cytotypes commonly referred to as river $(2 n=50)$ and swamp buffalo $(2 n=48)$. Several cytogenetic studies have been carried out to define the conventional karyotype (FISCHER \& UlbRICH, 1968 ; ChandRa, 1968 ; DE HondT \& Ghanam, 1971 ; Bongso, 1977) as well as the distribution of constitutive heterochromatin and the G-banding pattern of this species (SCHEURMANN et al., 1974 ; Römmelt, 1976 ; Gupta \& Ray-Chaudhuri, 1978 ; Cribiu \& Obeidah, 1978 ; YADAV \& BALAKRISHNAN, 1982). As in cattle, routine analysis of banded chro-

This work was supported by grant no. CT 81-00723-06 of the Research National Council of Italy, Rome. 
mosomes of buffalo has been limited so far by the fact that the G-banding procedure rarely provides enough resolution for a definite identification of the several small acrocentric chromosomes of the karyotype.

Among the various banding techniques available today, acridine orange $\mathrm{R}$-banding after late BrdU incorporation (RBA technique) (DUTRILLAUX et al., 1973) has proved to be the most suitable for routine analysis and identification of metaphase chromosomes of domestic animals. This procedure has been already successfully applied in cattle (Popescu, 1975 ; Gustavsson \& Hageltorn, 1976 ; Di Berardino et al., 1979), and contributions to a " standard " RBA-banded karyotype for this species have been recently proposed (Di BERARDino \& IANNUZZI, 1982 ; POPESCU et al., 1982).

In buffalo (Bubalus bubalis L.) the RBA technique has been used to study the distribution of Ag-NORs in river and swamp buffalo, as well as for tracing cytotaxonomic relationships with cattle (DI BERARDINO et al., 1981 ; DI BERARDINO \& IANNUZZI, 1981), but a standard banded karyotype is still lacking.

This paper presents the river buffalo RBA-banded karyotype and its diagrammatic representation which can be considered as a "model " until a conclusive definition of the standard is reached.

\section{Material and methods}

Peripheral blood was drawn from the jugular vein of 4 bulls and 2 cows river buffalo reared at Torre Lupara farm (Caserta, Italy). All of them had normal chromosome complement $(2 n=50) .1 \mathrm{ml}$ of plasma, obtained by spontaneous sedimentation of $10 \mathrm{ml}$ of heparinized whole blood, was cultured for $72 \mathrm{~h}$ in $10 \mathrm{ml}$ of McCoy's $5 \mathrm{~A}$ modified medium supplemented with L-glutamine $(0.1 \mathrm{ml})$, antibiotic-antimycotic mixture $(0.1 \mathrm{ml})$, phytoemagglutinin-M $(0.1 \mathrm{ml})$ and autologous plasma $(20 \mathrm{p} .100)$ obtained by centrifuging the sedimented blood at 3000 r.p.m. for $10 \mathrm{~min} .5^{\prime}-\mathrm{BrdU}$ was added to the cultures 7 hours before harvesting $(10 \mu \mathrm{g} / \mathrm{ml}$ final concentration). Colcemid was added $1.5 \mathrm{~h}$ prior to harvesting $(0.05 \mu \mathrm{g} / \mathrm{ml}$ final concentration).

The cell suspension was swelled in hypotonic $(0.075 \mathrm{M} \mathrm{KCl})$ for $20 \mathrm{~min}$ at $37{ }^{\circ} \mathrm{C}$, fixed 2 times in methanol-acetic acid $(3: 1)$ and left in fixative overnight in a refrigerator.

The air-dried slides were stained for $10 \mathrm{~min}$ in acridine orange solution $(0.2 \mathrm{p}$. 100) in phosphate buffer $0.15 \mathrm{M}(\mathrm{pH}=7.0)$, rinsed thoroughly in tap water and deionized water, then mounted in the same phosphate buffer and sealed with paraffin. A Leitz Dialux, equipped with a Ploem system was used. The photomicrographs were taken on Kodak microfilm recordak 5786 and printed on Ilfospeed paper no. 3 .

\section{Results}

Figure 1 shows a representative RBA-banded karyotype of river buffalo ( $2 n=50$, $\mathrm{XY}$ ). The 5 biarmed pairs have been arranged according to the centromeric index measurements reported by GUPTA \& RAY-CHAUDHURI (1978); the acrocentric chromo- 


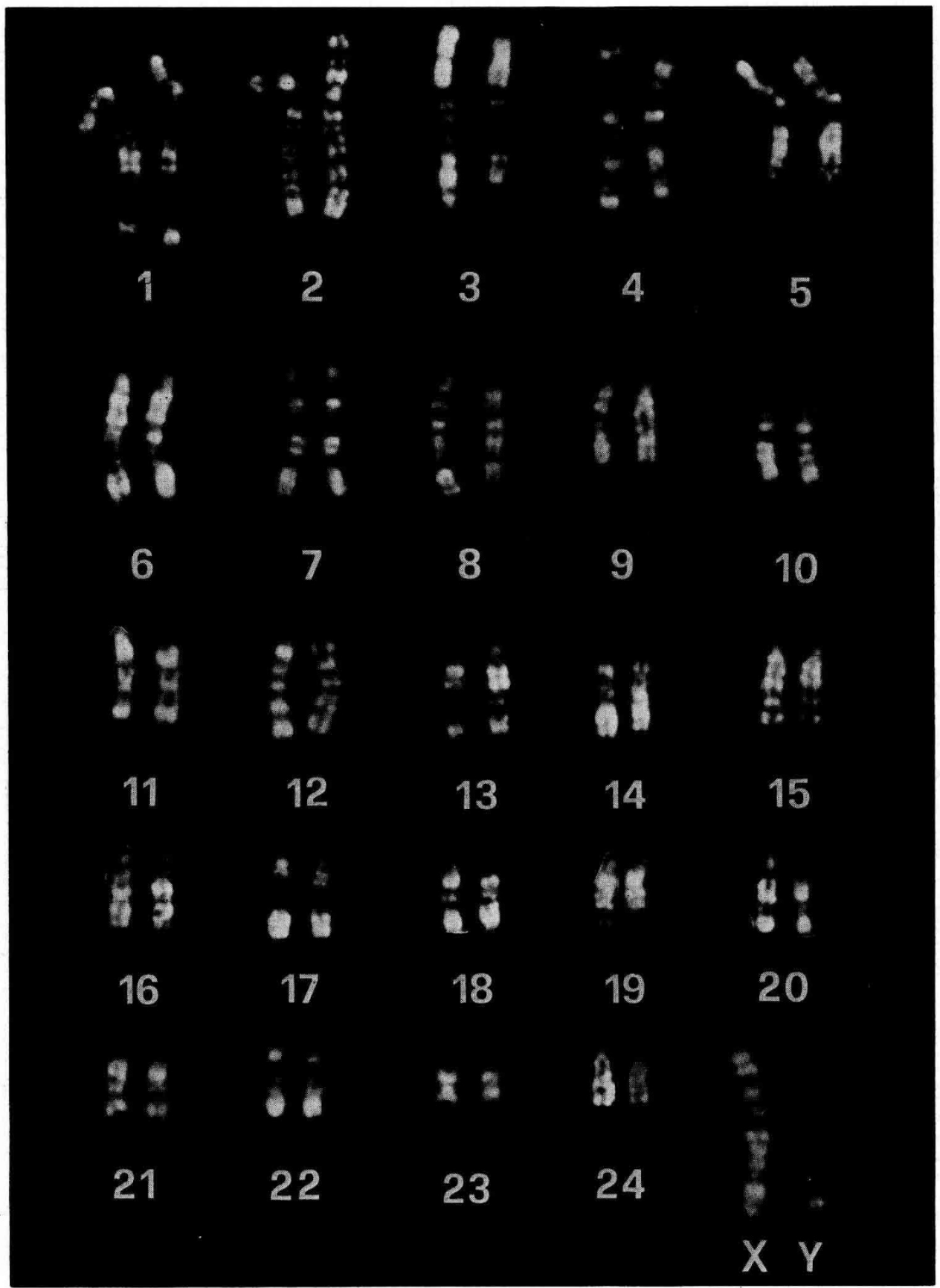

FIG. 1

Representative RBA banded karyotype of river buffalo $(2 \mathrm{n}=50, X Y)$.

Caryotype à bandes $R(R B A)$ du buffle de rivière $(2 \mathrm{n}=50, X Y)$. 


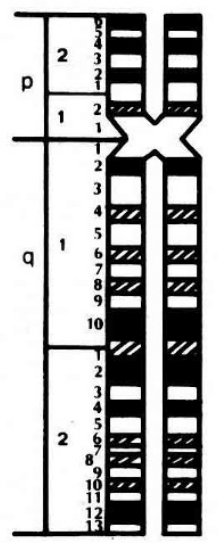

1

1-29

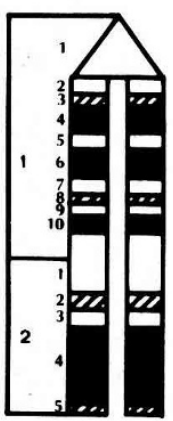

6

3
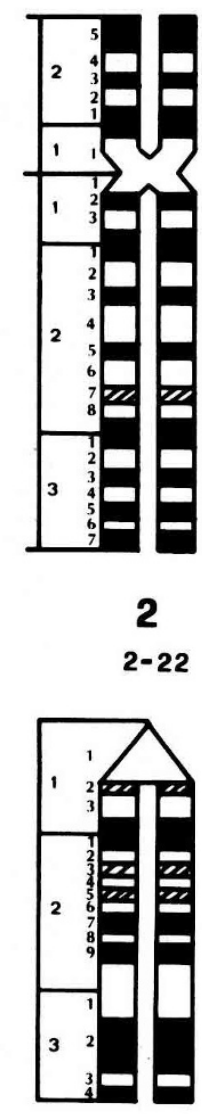

7
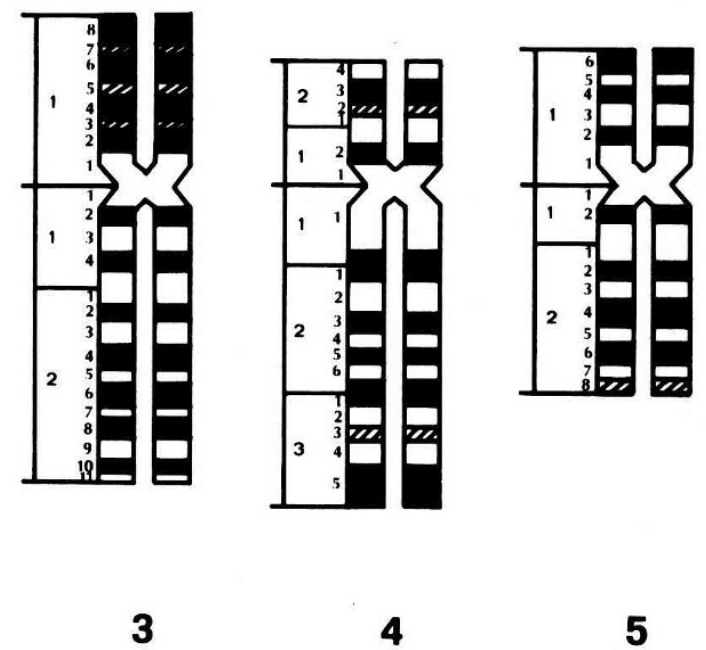

8-19

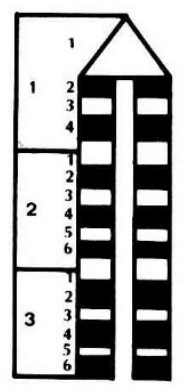

8

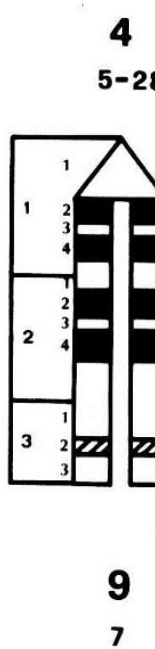

5

16-25

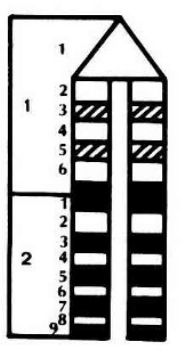

10 

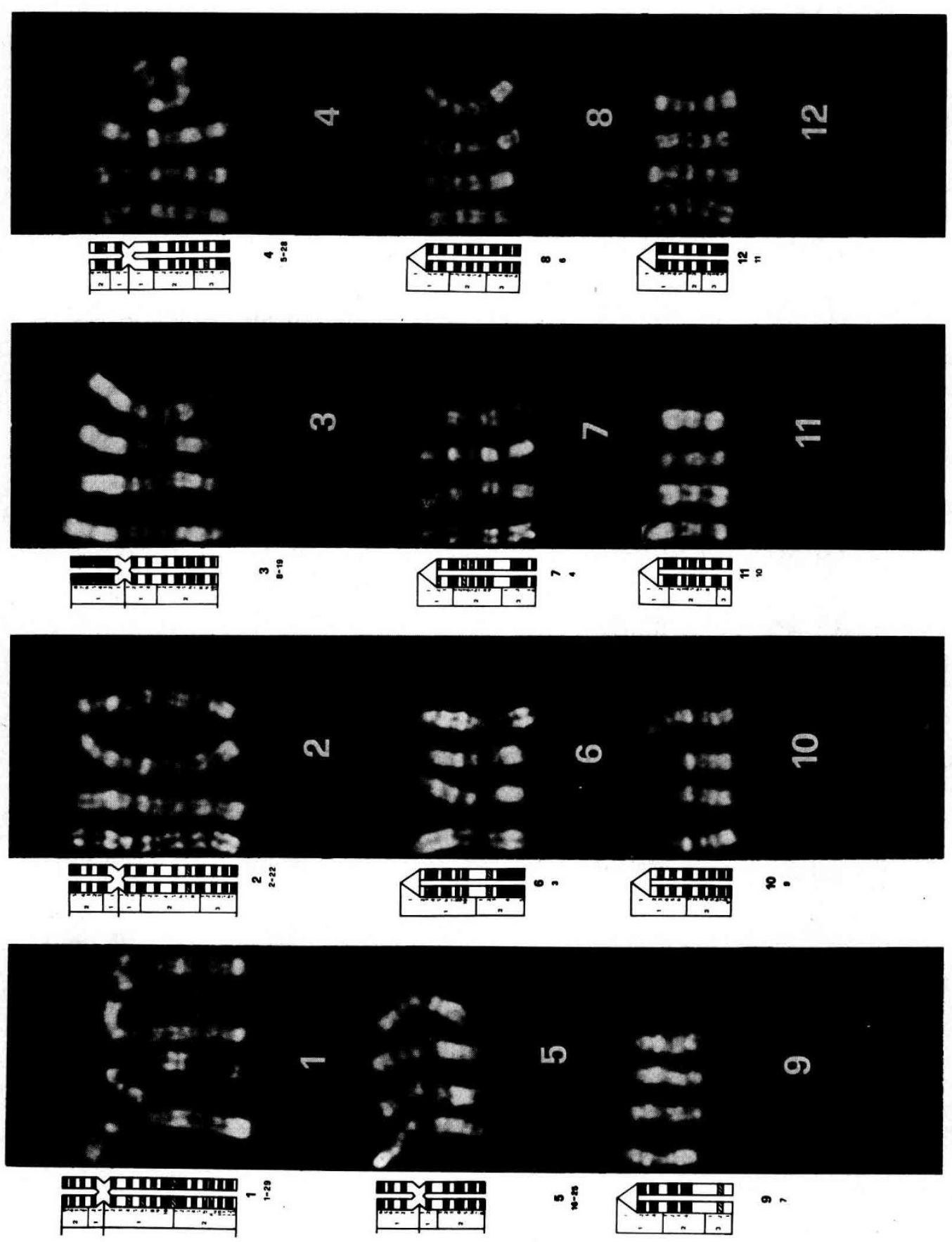

FIG. 2 A-B

$R B A$-banding pattern of individual river buffalo chromosomes.

Bandes $R$ (RBA).

Groups of 4 representative chromosomes from different karyotypes were used to construct the diagrammatic RBA banding pattern shown on the left of each group.

Une représentation schématique de chaque chromosome a été effectuée à partir de 4 chromosomes représentatifs pris dans différents caryotypes. 


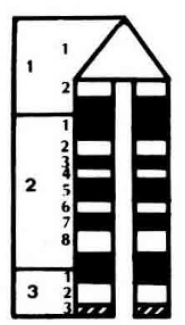

11

10

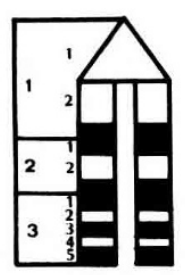

16

15

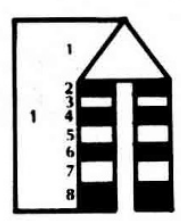

21

23

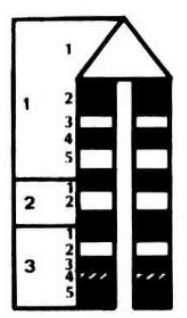

12

11

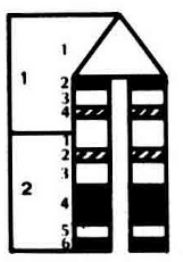

17

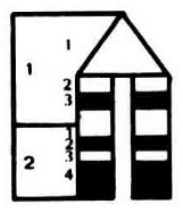

22

24

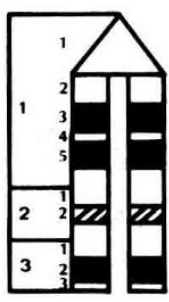

13

12

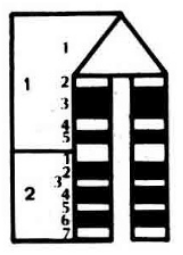

18

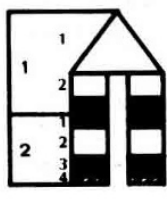

23

26

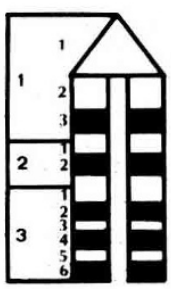

14

13

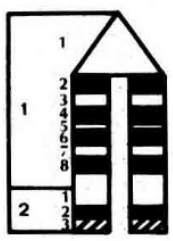

19

20

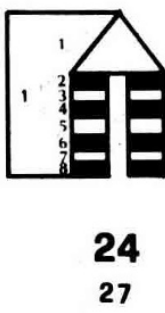

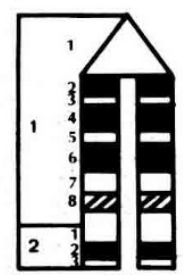

15

14

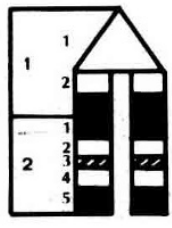

20

21

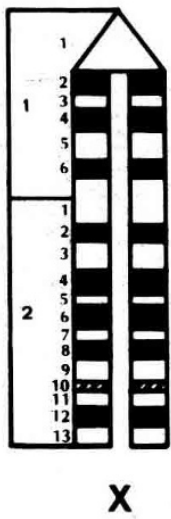

Positive $\mathbf{R}$ bands

Negative $R$ bands

Variable $R$ bands

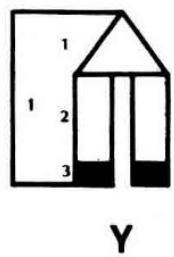




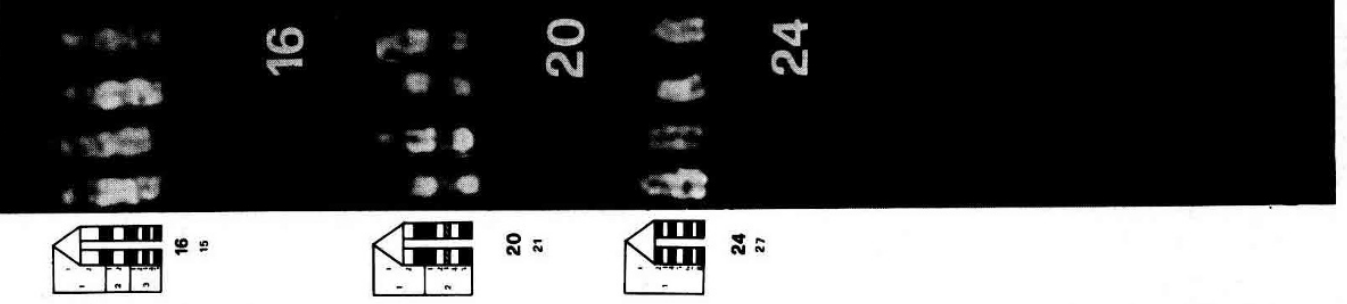
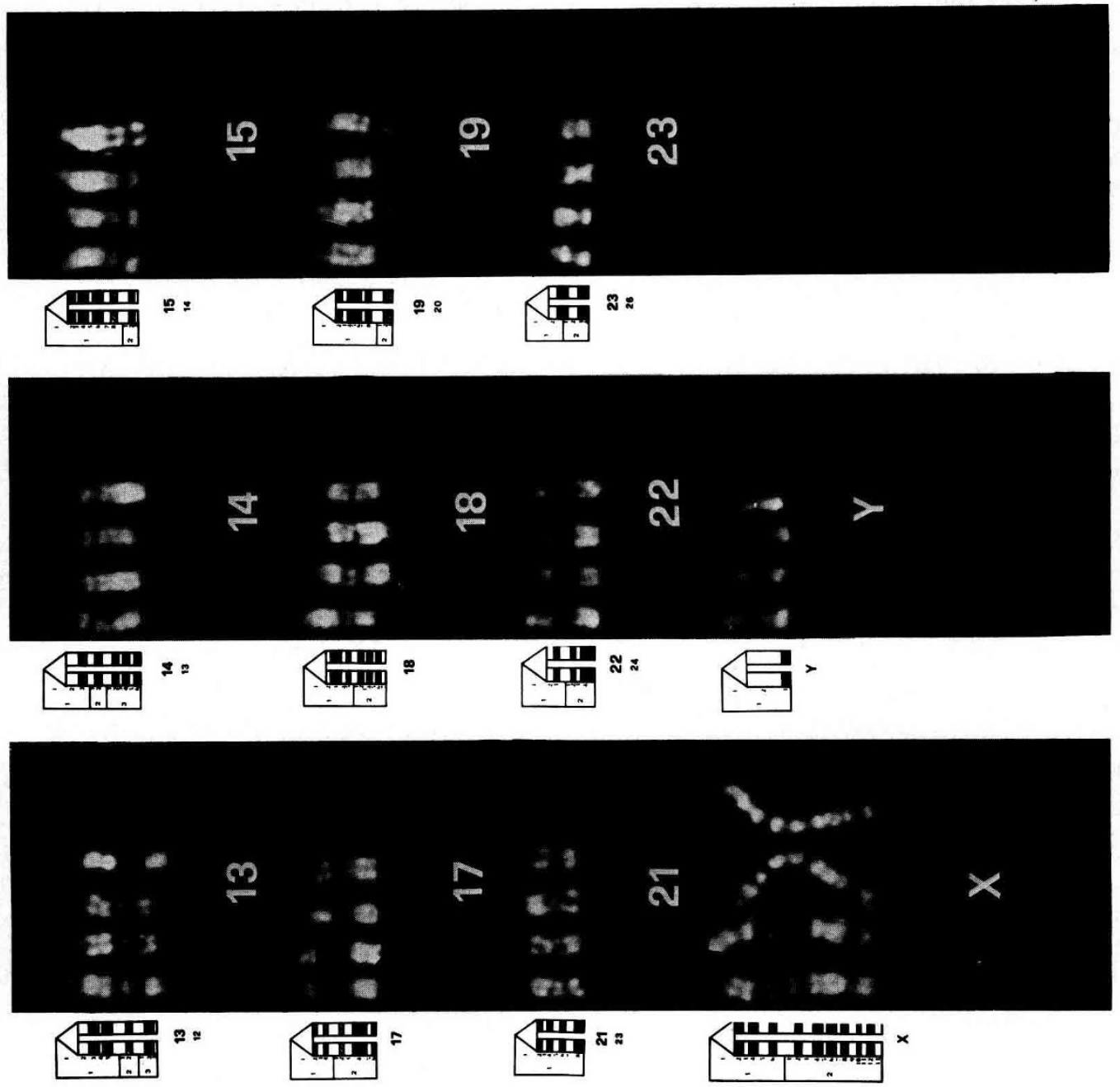

Fig. 3 A-B

Diagrammatic representation of the RBA-banded karyotype of river buffalo.

Représentation schématique du caryotype à bandes $R(R B A)$ du buffle de rivière.

The small numbers below the buffalo nomenclature indicate the corresponding homologues of the standard karyotype of cattle; chromosomes 17 and 18 of buffalo have the same position in the cattle karyotype.

Les nombres situés au-dessous de ceux du buffle représentent la place de ces chromosomes dans le caryotype standard du bœuf domestique. Les chromosomes 17 et 18 du buffle ont la même position que dans le caryotype du bouf. 
somes from pair no. 6 to pair no. 24 were arranged according to the standardized nomenclature of cattle chromosomes, as defined by the READING CONFERENCE (1980).

For each pair, figure 2 A-B shows 4 representative RBA-banded chromosomes used to construct the diagrammatic banding pattern reported in figure $3 \mathrm{~A}-\mathrm{B}$. The small numbers below the buffalo nomenclature indicate the corresponding cattle chromosomes. Given the extensive variation in C-band size, the centromeric length was kept constant for all the chromosomes. The system used in numbering the bands follows the International System Chromosome Nomenclature for the human karyotype (I.S.C.N., 1978). follows :

The identifying features of the R-banded chromosomes of river buffalo were as

\section{Chromosome}

\section{Features}

$1 \mathrm{p} \quad$ Corresponds to cattle chromosome no. 29. A negative subcentromeric band (21) is followed by 3 positive bands, the last 2 being the most prominent.

$1 \mathrm{q}$ Corresponds to cattle chromosome no. 1. Three brilliant positive bands : 2 centrally located $(1,10$ and 22$)$ and often joined, 1 terminal $(2,12)$.

$2 \mathrm{p}$ Corresponds to cattle chromosome no. 22. Two brilliant positive bands : 1 proximal (21), the other (25) terminal.

$2 \mathrm{q}$ Corresponds to cattle chromosome no. 2. Three brilliant positive bands : 1 proximal (21), 1 distal (31) and 1 terminal including 2 bands (35 and 37) which are often joined.

$3 \mathrm{p}$ Corresponds to cattle chromosome no. 19. Uniformly brilliant because of 4 positive bands very close to each other.

$3 \mathrm{q}$ Corresponds to cattle chromosome no. 8. Three brilliant positive bands $(24,26$ and 28$)$ are very closely located in the distal half of the chromosome.

$4 \mathrm{p} \quad$ Corresponds to cattle chromosome no. 28. A negative centrally located band (21) separates 2 brilliant positive bands, 1 subcentromeric (12) and 1 distal (23).

$4 \mathrm{q}$ Corresponds to cattle chromosome no. 5. A brilliant proximal band (21) and a distal brilliant region which includes only 1 positive band (35).

$5 \mathrm{p}$ Corresponds to cattle chromosome no. 25. A proximal positive band of medium intensity (12), a negative band (13) and 2 brilliant terminal bands (14 and 16).

$5 \mathrm{q} \quad$ Corresponds to cattle chromosome no. 16. A large proximal negative band (21) is followed by a broad distal region with 3 positive bands, one of which (24) is the most prominent.

6 Corresponds to cattle chromosome no. 3. A large negative band (21) divides the chromosome in 2 brilliant regions, 1 proximal and 1 distal.

7 Corresponds to cattle chromosome no. 4. A brilliant proximal band (21) and a distal large negative band (31) divide the chromosome in 3 regions ; the distal band is brilliant, including a large (32) and a small (34) terminal band.

8 Corresponds to cattle chromosome no. 6. Two negative bands, 1 proximal (21) and 1 distal (31), interrupt a uniform banding pattern of medium intensity. 
9 Corresponds to cattle chromosome no. 7. Four brilliant positive bands, 2 proximal and 2 central ; the distal 3rd of the chromosome is negative with a variable band (32).

10 Corresponds to cattle chromosome no. 9. A brilliant positive band (21), centrally located, divides the chromosome in a pale proximal half and a distal region with 4 positive bands.

11 Corresponds to cattle chromosome no. 10. Two brilliant positive bands, 1 subcentromeric (21) and 1 distal (31), are separated by 3 positive bands, one of which (25) is more prominent.

12 Corresponds to cattle chromosome no. 11. Two positive bands, centrally located and equally spaced (21 and 31 ) separate 2 proximal bands from 2 distal ones which are often joined.

13 Corresponds to cattle chromosome no. 12. Two brilliant positive bands (13 and 15) in the proximal half of the chromosome; 2 negative bands (21 and 31) in the distal half with a variable band (22) in between.

14 Corresponds to cattle chromosome no. 13. The proximal half of the chromosome includes 2 positive bands (13 and 22 ) separated by a prominent negative band (21); the distal half is brilliant.

15 Corresponds to cattle chromosome no. 14. The proximal half is brilliant ; the distal half is largely negative with a positive terminal band (22).

16 Corresponds to cattle chromosome no. 15. Two brilliant positive bands (21 and 31) are centrally located.

17 Corresponds to cattle chromosome 17. One large proximal negative band (21) and 1 brilliant positive band (24) distally located.

18 Corresponds to cattle chromosome no. 18. A negative centrally located band (21) divides the chromosome in 2 brilliant regions.

19 Corresponds to cattle chromosome no. 20 . The proximal $2 / 3$ of the chromosome are brilliant ; a prominent negative band (21) is distally located.

20 Corresponds to cattle chromosome no. 21. Two brilliant positive bands ; the one centrally located (21) is larger than the terminal one (25).

21 Corresponds to cattle chromosome no. 23. Four positive bands equally spaced; the terminal band (18) is the most prominent.

22 Corresponds to cattle chromosome no. 24. A negative centrally located band (21) is followed by a brilliant distal region.

23 Corresponds to cattle chromosome no. 26. A large brilliant positive band (21) is centrally located.

24 Corresponds to cattle chromosome no. 27. Four positive bands uniformly distributed.

X Largest acrocentric showing 5 brilliant positive bands, 2 of which (12 and 14) are subcentromeric; the other 3 (24, 26 and 28) are distally located. Two other positive bands (16 and 22), centrally located, appear of medium intensity in some preparations, brilliant in others.

Y Small acrocentric, almost entirely R-negative, with a positive band of medium intensity at the telomeres. Unlike the G-banding, this unique $\mathrm{R}$-banding pattern makes this chromosome easily identifiable among the small acrocentrics, thus allowing a quick sex determination. 


\section{Discussion and conclusion}

Unlike cattle, the buffalo has been the subject of little cytogenetic research, as demonstrated by the fact that even the Reading Conference on the standardization of banded karyotypes of domestic animals neglected this species because of insufficient cytogenetic data. Since the detection of chromosomal abnormalities and their eradication from livestock populations are fundamental steps in any genetic improvement program, it is necessary to undertake cytogenetic screening of buffalo populations, especially those under selection, by using a reliable banding technique for routine analysis and by adopting à " standard " banded karyotype for correct identification and classification of the chromosomes involved in numerical and structural rearrangements.

The present paper confirms the suitability of the RBA technique for detailed description and definite identification of chromosomes of domestic animals and proposes a " model" for the RBA-banded karyotype of river buffalo which could be used as a " standard" after being improved by contributions from other investigators. The model presented here is based on prometaphase chromosomes and, therefore, is far more resolutive and descriptive than previous RBA-banded karyotypes (DI BERARDINO et al., $1980,1981)$, which were derived from more contracted chromosome preparations.

In a previous paper by GUPTA \& RAY-CHAUDHURI (1978), attempts were made to trace chromosome homologies between river buffalo and Bos indicus; on the basis of morphometric measurements and their own G-banding system, the authors reported the 5 biarmed pairs of river buffalo were equivalent to chromosomes $1 / 26,2 / 25,8 / 21,6 / 28$ and $16 / 27$ of Indian cattle, whereas no indications were provided for the remaining acrocentrics from 6 to 24 . Our results show that all river buffalo autosomes are similar in R-banding pattern to cattle autosomes : the 5 biarmed pairs of river buffalo correspond to chromosomes $1 / 29,2 / 22,8 / 19,5 / 28$ and $16 / 25$ of the standardized nomenclature for cattle (READING, 1980) ; the remaining autosomes from 6 to 24 are also similar in banding pattern to cattle autosomes, thus confirming our previous observations (DI BERARDINO et al., 1981 ; Di BERARDINO \& IANNUZZI, 1981).

The little amount of constitutive heterochromatin in the 5 biarmed pairs of river buffalo (CRIBIU \& OBEIDAH, 1978 ; GuPTA \& RAY-ChAUdHURI, 1978 ; YADAV \& BALAKRISHNAN, 1982), also found in swamp buffalo (DI BERARDINO \& IANNUZZI, 1981), suggests that variable amounts of $\mathrm{C}$-band material might have been lost (or gained) from one or both centromeres during the centric fusion (or fission) process. These events, however, remain to be elucidated, especially in relation to the origin of the large block of constitutive heterochromatin in the buffalo $\mathrm{X}$ chromosome.

Given the extensive banding homologies among the Bovidae (BUCKLAND \& EVANS, 1978 ; Di BerARDino et al., 1981 ; Di BERARdino \& IANNUZZI, 1981), it might be suggested that any given chromosome of buffalo, as well as other members of the family, be numbered, not according to the rank-position that it occupies in the karyotype, but according to the corresponding nomenclature of the standardized karyotype of cattle. Beside the fact that banding homology does not mean genetic identity, this new system of nomenclature would improve understanding of evolutionary relationships among species and subspecies ; in our opinion, it is rather difficult (and not practical) to remember the position that each chromosome occupies in the different karyotypes of different species. After all, this problem was already approached by BUCKLAND \& EVANS (1978) who established cytotaxonomic relationships between several Bovidae by taking the goat karyotype as a reference. 


\section{References}

Bongso T.A., 1977. The karyotype of the indigenous buffalo (Bubalus bubalis) of Sri Lanka. Ceylon Vet. J., 25, 9-11.

BuCKLAND R.A., Evans H.J., 1978. Cytogenetic aspects of phylogeny in the Bovidae. I. - G-banding. Cytogenet. Cell Genet., 21, 42-63.

ChANDRA H.S., 1968. Chromosomes of Asian water buffaloes, Bubalus bubalis (Linnaeus). Mamm. Chrom. Newsl., 9, 231-236.

Cribiu E.P., OBEIDAH A., 1978. The C-banding pattern of the Egyptian Water Buffalo (Bubalus bubalis). Ann. Génét. Sél. Anim., 10, 271-274.

DE Hondt H.A., Ghanam S.A., 1971. Cytogenetic studies of Egyptian Water Buffalo (Bubalus bubalis). Z. Tierzucht. ZuchtgsBiol., 88, 64-88.

Di Berardino D., Iannuzzi L., Ferrara L., Matassino D., 1979. A new case of Robertsonian Translocation in cattle. J. Hered., 70, 436-438.

Di Berardino D., Iannuzzi L., Bettini T.M., Matassino D., 1980. Karyotype evolution in cattle (Bos taurus) and buffalo (Bubalus bubalis). $4^{\text {th }}$ European Colloquium on Cytogenetics of Domestic Animals, Uppsala, June 8-13 1980, 272-288.

Di Berardino D., Iannuzzi L., Bettini T.M., Matassino D., 1981. Ag-NoRs variation and banding homologies in two species of Bovidae : Bubalus bubalis and Bos taurus. Can. J. Genet. Cytol., 23, 89-99.

Di Berardino D., Iannuzzi L., 1981. Chromosome banding homologies in Swamp and Murrah buffalo. $J$ Hered., 72, 183-188.

Di Berardino D., IANNUZZI L., 1982. Detailed description of R-banded bovine chromosomes. $J$. Hered., 73, 434-438.

DutrillauX B., Laurent C., Couturier J., Lejeune J., 1973. Coloration des chromosomes humains par l'acridine orange après traitement par la 5-Bromodeoxyridine. C.R. Acad. Sci., Sér. $D, 276,3179-3182$.

Fischer H., Ulbrich F., 1968. Chromosomes of the Murrah buffalo and its crossbreeds with Asiatic Swamp Buffalo (Bubalus bubalis). Z. Tierz. ZuchtgsBiol., 84, 110-114.

GuPTA P., RAY-Chaudhuri S.P., 1978. Robertsonian changes in chromosomes of Indian Murrah buffalo, Bubalus bubalis. The Nucleus, 21, 90-97.

Gustavsson I., Hageltorn M., 1976. Staining technique for definite identification of individual cattle chromosomes in routine analysis. $J$. Hered., 67, 175-178.

I.S.C.N., 1978. An international system for human cytogenetic nomenclature. Cytogenet. Cell Genet., 21, 309-404.

POPESCU C.P., 1975. Essai d'identification des chromosomes bovins (Bos taurus) à l'aide du marquage au 5-bromodeoxyuridine (BrdU). $2^{e}$ Colloque Européen de Cytogénétique des Animaux Domestiques, Giessen, 29-30 sept., 59-64.

Popescu C.P., RonNe M., Cribiu E.P., BosCher J., 1982. The standardization of R-banded karyotype in cattle. $5^{\text {th }}$ European Colloquium on Cytogenetics of Domestic Animals, Milano, Gargnano, June 7-11 1982, 172-190.

Reading Conference, 1980. Proceedings of the first International Conference for the Standardization of Banded Karyotype of Domestic Animals. Hereditas, 92, 145-162.

Römelt C., 1976. Karyotypidentifikation mit Hilfe der G- und C-Banden-Technik beim Sumpfund Murrah-Büffel. Dissertation, Justus-Liebig Universität, Giessen.

Scheurmann E., Wiesner R., Fischer H., Jainudeen M.R., 1974. Karyotyp, C-banden und Identifizierung des Geschlechtschromossomen des Ceylonesischen Wasserbuffels (Bubalus bubalis). Giessener Beitr. Zuchtchyg., 6, 1-7.

YADAV B.R., BALAKRishnan C.R., 1981. On the Y chromosome of the Murrah buffalo (Bubalus bubalis). Can. J. Genet. Cytol., 24, 189-192. 